Cook, J. \& Oliver, M. (2002) Designing a toolkit to support dialogue in learning. Computers and Education, 38 (1-3), 151-164.

http://dx.doi.org/10.1016/S0360-1315(01)00076-8 


\title{
Designing a toolkit to support dialogue in learning
}

\author{
John Cook $^{11}$ and Martin Oliver ${ }^{2}$ \\ ${ }^{1}$ Adaptive Learning Environment Research Team, School of Computing Science, Middlesex University, \\ Trent Park Campus, Bramley Road, London N14 4YZ, UK \\ ${ }^{2}$ Higher Education Research and Development Unit, University College London, 1-19 Torrington Place, \\ London WC1E 6BT, UK
}

\begin{abstract}
Whilst the use of dialogue has many pedagogic advantages to offer Higher Education, implementing it effectively in teaching practice is a complex and problematic process that requires a wide range of expertise. This paper describes one strategy for addressing this issue: the development of a toolkit that supports the process of planning and reflection that practitioners must engage in when attempting to use dialogue in their teaching. After identifying and illustrating some of the issues relating to the use of dialogue, the notion of toolkits will be defined and a methodology for their development outlined. This is then exemplified with the specific case of the design of a toolkit for using dialogue in learning. A study is then described in which this prototype toolkit was evaluated, demonstrating its impact both in terms of changing practice and of developing a critical awareness of the issues relating dialogue and learning, before conclusions are drawn about the wider relevance of the work.
\end{abstract}

\footnotetext{
${ }^{1}$ Corresponding author: e-mail: j.cook@mdx.ac.uk, fax: ++44 (0)20 84115924
} 
Keywords: pedagogical issues, teaching/learning strategies, improving classroom teaching.

\section{Introduction}

Although there has been an interest in the role of dialogue in learning since Ancient Greek times, there has been a recent resurgence, which can partly be attributed to the new Internet-based technologies that enable asynchronous communication in Virtual Learning Environments (VLE), as discussed for example by Boyle \& Cook (2001). Doubtless this interest will gain momentum as we start to take advantage of new mobile technologies. However, the technology should not be allowed to dictate the nature of the educational resource, as is so often the case - one of five current strategic issues identified by Harasim (2001) was the notion of principled design (as opposed to the consumption of technology). In this paper we address this concern by outlining the development of an approach that allows practitioners to use dialogue in learning in an educationally driven way.

One particular problem in this context is that there is a proliferation of techniques for using dialogue to support learning; there is no single "correct" approach that will meet all pedagogic aims. This problem will be particularly acute for practitioners without a research interest in the area; we expand on this issue in Section 2. In addition, practitioners will need to develop (or at the least, gain access to) the necessary expertise to be able to apply a given method effectively. To address these problems, we decided to design a 'toolkit' - a decision support tool - that helps tutors think about ways of using dialogue to support learning. In Section 3 we describe the generic concept of 
toolkits; this is followed in Section 4 by our proposal for a toolkit for dialogue in learning. A study is then described, in Section 5, in which this prototype toolkit was evaluated, demonstrating its impact. Conclusions are drawn in Section 6 about the wider relevance of the work.

\section{Dialogue in learning}

The idea that dialogue can help to promote learning is not new. The main problem for a tutor wishing to apply dialogue to a learning situation is that, as we point out above, there are a range of approaches and theoretical perspectives to draw upon. Whilst we recognise that there are also a number of important issues to address once such a choice has been made (for example, engagement and commitment, initiative handling, focus control, etc.), at this stage in our research we are concerned with the first step only: the problem of selecting one possible approach to using dialogue in a learning situation. In order to illustrate the differences between approaches, any of which may be important in addressing particular teaching and learning needs, three different approaches are briefly described below: Socratic dialogue, dialogue games and communities of inquiry.

In the Meno dialogue, Socrates (Plato, 1924) used repeated questioning to get a slave boy to discover for himself that the area of a square can be doubled by multiplying each side by the square-root of 2 . True Socratic dialogue was used to prepare Athenian males for their role in society and employs such techniques as hypothesis entrapment. One modern interpretation of Socratic dialogue is that of a question and answer session between tutor and learner. The WHY computer-based system (Stevens, Collins \& Goldin, 1982) represented an early attempt, based on a study of human tutoring, to 
formalise the Socratic method for tutoring about the rainfall processes. More recently, some of the WHY researchers have followed up their own work (Collins \& Stevens, 1991) by proposing a theory of inquiry teaching that includes elements of Socratic tutoring.

Dialogue games attempt to provide a formal set of rules to facilitate turn taking in a dialogue. Thus interactions can be facilitated as a prescriptive dialogue game (e.g. Levin \& Moore, 1977) where participants have defined roles and rules of engagement that regulate the participants as they make moves in the dialogues. Baker (1989) describes a system called KANT for interactions revolving around the identification of phrase boundaries for very restricted musical genres. KANT attempts to engage in explicit negotiation strategies, based on dialogue games, with the aim of promoting metacognitive thinking, specifically belief revision in learners and prompting critical arguments in dialogues about music.

By way of contrast with the preceding methods, Lipman (1991) has proposed that education should include reasoning and judgement about knowledge. Education in the Lipman sense of the word is not 'simply' learning, it is a Vygotskian-like teacherguided community of inquiry that places an emphasis on social interaction and cooperative learning. For Vygotsky (1978), human mental functions appear first as inter-individual (e.g. dialogue) and then intra-individual; that is, by the use of socially developed tools, both technological and psychological. Lipman calls his approach 'the reflective model of education practice'. This educational theory emphasise the need for teacher mediated reflection about problem-solving through dialogue. Lipman's reflective model of education practice has been used as the guiding educational theory for a pedagogical agent called MetaMuse (Cook, 2001). MetaMuse is a learning 
assistant that was designed to promote collaborative dialogues about musical composition ideas.

As we shall see below, the differences between the above approaches surface when they, and other approaches, are considered for application in different subject areas and learning contexts. For example, Socratic dialogue is typically seen as a one-to-one approach that is amenable to scientific inquiry. However, if a tutor is working in an open domain where there is typically no single correct solution (for example, see Cook, 2001), then a more open style of interaction, i.e. a community of inquiry, may be appropriate. On the other hand, the TAPS Project (Derry, 1992) found that complexity is a major problem in employing the apprenticeship model of the community of inquiry approach. TAPS is a learning environment designed to help learners tackle Arithmetic story problems; it attempted to use a Vygotskian approach where the student is cognitive apprentice and the system is a cooperative mentor.

It is against this background of diverse perspectives that we decided to design a toolkit that helps tutors think about ways of using dialogue to support learning. Such an undertaking is non-trivial. In order to lay the foundations to our chosen solution, in the next section we describe the general concept of toolkits.

\section{Generic toolkits}

One approach to supporting decision making involves the development of 'toolkits' resources that incorporate an expert model of the design process, together with activities that help the user to select appropriate options at each step (Oliver \& Conole, 1999). These resources provide an alternative to both theoretical frameworks and to 
software wizards. Theoretical frameworks are flexible and versatile in the way that they can be used to analyse practical problems, but do not necessarily contain the kind of cues or procedures that would be required to guide decision making about a particular problem. Software wizards, on the other hand, are tightly focused and constrained but are designed to guide the user through decision making. Toolkits represent a compromise between these two positions: they provide a structure for decision making, and make recommendations based on 'goodness of fit' between descriptions of a problem provided by the user and descriptions of possible solutions provided by the designers. The methodology for toolkit design incorporates a number of stages which are described in detail elsewhere (Conole \& Oliver, in press); these are summarised below.

\subsection{Identification of a suitable theoretical framework for design}

Because toolkits are designed to support design and planning, they are structured around a model of the planning process. In some cases, an expert model will already exist; in others, it is necessary to derive the model from relevant theories or, if necessary, case studies. This model will provide a frame of reference and an initial structure for decision-making.

3.2 Toolkit specification: how can the range of options available at each stage be translated into a practical but flexible form of guidance for non-experts?

At this stage of development, a prototype toolkit is drawn up, based on the framework, which will include the description and structuring of the options (a knowledge base) open to users at each decision making step. This must be presented as a series of activities or choices that allow the user to interrogate the options available. The information must also be organised in layers of increasingly detailed material so as to 
support flexible use, allowing users to bypass sections with little or no relevance to them or engage deeply with content that they find important.

\subsection{Toolkit refinement: how useful and flexible is the toolkit?}

Once a prototype toolkit has been developed, it is tested with end users and evaluated to assess its suitability, ease of use, flexibility and relevance. In particular, feedback from this formative evaluation stage is used to highlight which aspects of the toolkit the users find most useful, and whether there are any important steps or resources omitted.

\subsection{Inclusion of user-defined features}

User trials are undertaken with a refined toolkit, in order to assess its flexibility and its suitability for adaptation by end users. Common adaptations, which are likely to be of wider value, can be incorporated into the core functionality of the toolkit at this stage.

\subsection{The development of shared resources}

Once the toolkit has been developed and tested, it is then populated with sample outputs from other users. These provide a rich resource bank that can be drawn upon for case studies, used as 'templates' that can be adapted, and so on.

\section{Developing a toolkit for dialogue in learning}

Following the above methodology, a prototype toolkit was developed for the topic of dialogue in learning. The main stages of this development process are described in the following sub-sections. 


\subsection{The derivation of an expert model for incorporating dialogue in learning}

No existing model could be found that described the process of comparing and contrasting different discursive formats for education. Consequently, a model was derived from consideration of relevant case studies. This incorporated the following steps:

1. Identification of learning need

2. Elicitation of learning objectives

3. Elicitation of detailed description of task and context

4. The filtering of options and recommendation of suitable approaches

5. Selection, investigation and adoption of a suitable approach by the user

The first step is intended to provide a record of the context in which dialogue is to be used, and the extent of the curriculum to which it is relevant. The purpose of this is to help the user to focus on pedagogic aspirations rather than, for example, the technical facilities provided by convenient systems or resources.

The next step involves developing this description by providing specific learning objectives. The intention is to elicit these in a specific format, and in particular, to identify the criteria by which the user will judge whether or not they have been met. Breaking down the course in this task-analytic way does present possible issues of fragmentation and loss of coherence within the course; these will be investigated in subsequent studies. However, at present, it is a necessarily reductionist step that makes the qualitative description of the course amenable to analysis. 
The third step is the last in which the system gathers information from the user. Here, each learning objective is presented in turn, and the user is asked to 'describe' them using a series of descriptive scales (detailed below). This description is then used as the basis of the filtering process (step four), which results in a shortlist of approaches being presented to the user for selection (step five). It should be noted that in order to support this final selection, it is necessary to provide 'layered' descriptions of each option. At the top layer is the name of the approach; by following a series of hyperlinks, the user can then access a short descriptive summary of the approach and, if it seems relevant, additional material including pointers to relevant research, case studies, 'how to' guides and so on.

4.2 The mapping of the knowledge space for each major decision point in the system design process

The major conceptual development within the toolkit involved comparing a range of approaches to using dialogue in learning, in order to identify a set of descriptors that could be used to differentiate between them. This process of differentiation is vital; it forms the basis for the recommendation of suitable options (based on the elicited description of learning objectives) and the rejection of unsuitable alternatives.

The range of methods considered during this review included open discussion, structured debates, role plays, Socratic dialogue, modern interpretations of Socratic dialogue, communities of inquiry, 'court of law' approaches and dialogue games. The following criteria were identified as useful ways of distinguishing between these:

- Whether or not it is important to reach a 'right' answer.

- Whether the method emphasises collaboration or competition. 
- The duration required for a dialogue of this type.

- The numbers of participants required.

- Issues of power relationships within the discussion.

It is important to note that these descriptors are not intended to be either exhaustive or exclusive; nor are they necessarily independent of each other. Their adoption (and the rejection of alternative descriptors) is based solely on their pragmatic value in discriminating between alternatives in a way that is likely to identify useful approaches. Consequently, the choice of these descriptors is one of the elements that will require validation as part of the toolkit's evaluation.

\subsection{The creation of selection tasks based on the knowledge map}

The selection task for this toolkit was easy to develop. As outlined above, the structure of this toolkit elicits increasingly abstracted information from users in order to make recommendations about suitable approaches. The final step in this process involves asking the user to rate each of their learning objectives using the same mapping that is used to describe methods in the knowledge base. As with the choice of descriptors, the number of categories within each option is a pragmatic choice that will require empirical verification. For the prototype toolkit the questions asked and the ranges permitted were as follows:

1. Is there a right/wrong answer? (Options: there is an absolute answer, there are criteria for 'right' answers, very open/free.)

2. Should the dialogue promote competition or collaboration? (Options: there will be clearly identified 'winners' and 'losers', the dialogue will be highly 
competitive, some people will do better than others, success will only be judged in terms of the group as a whole, credit will be given for listening to others and drawing on evidence.)

3. What will the duration be? (Options: hours, days, months.)

4. What will the group size and level of tutor support be? (One interval, e.g. "2530 students", one integer.)

5. Issues of power (who defines rules and roles?) (Options: defined and assigned by the tutor, negotiated between tutor and participants, determined by participants, no formalisation of power/roles.)

\subsection{The filtering and presentation of approaches}

Once the information requested above has been elicited from the user, an algorithm is used to search through the database of approaches and test each for 'goodness of fit'. This is measured in terms of the number of categories difference between the approach and the ideal described by the user for each descriptor. These scores can be combined in a variety of ways, the most simple (currently being tested) involving summing these differences and ranking the options. In cases where an approach is a good fit in all but one category, these are presented as alternatives that may or may not be suitable. Suggestions are presented to the user as follows:

"Your top 3 recommendations are..."

1. [Something]

2. [Something] 


\section{3. [Something]}

"You might also consider..."

1. [something that nearly fits profile]

2. [something that nearly fits profile]

It is at this point that users will access further information about each of the methods, following a series of hyperlinks starting with the names of the approaches that were suggested.

The result of this design process is a prototype toolkit that enables practitioners to produce plans, complete with advice and guidance, for the implementation of a system.

\section{Evaluation of the toolkit}

The development process described above resulted in a paper-based prototype system. Given the numerous pragmatic decisions required by the development process, it was decided that it would be appropriate to pilot this prototype prior to its implementation as a software tool. Previously developed toolkits have been piloted using workshops or case studies that involve practitioners working through the toolkit (paper-based or otherwise) following a talk-aloud protocol. However, to support the implementation of the prototype as a system, it was decided that it would be more appropriate to evaluate the toolkit using a "Wizard of Oz" (WoZ) technique (see for example Winkels, 1992, pp. 28; or Faulkner, 2000, pp. 166) to emulate interactions with the system. This involved the designers developing a script covering the possible interactions with the toolkit, and taking on the role of system. Users interacted with the 'system' via email, 
using the prompts and formats intended for use in the system. This had the advantage of allowing otherwise unredeemable breakdowns to be recorded and dealt with swiftly.

The specific aim of this study was to test the concept, and also to test the intended prompts and feedback that would be incorporated into the system. Four separate trials were run, each involving a series of exchanges with one participant. Three participants worked as lecturers in software engineering; the fourth taught a course in Dentistry, and was chosen in order to broaden the sample. All participants had previous experience of attempting to use dialogue (and specifically, computer-based communication) to support learning, but none considered themselves to be an expert in this area. This level of expertise allowed them to engage with real, meaningful problems, but also to provide a relatively informed critique of whether or not the toolkit was useful to them. Importantly, participants were also asked whether or not they would have used dialogue differently in their courses had they been able to work through the toolkit.

The following sub-sections illustrate themes that arose from the study, illustrated with excerpts from the WoZ email transactions and subsequent discussion with participants.

\subsection{What sort of information was given by participants?}

Table 1 illustrates the type of interactions typical to the study, using examples from the WoZ sessions with Participant 1, a software engineer. Participant 1's response to question 3 is of particular interest, as it spells out his specific pedagogic goal of wanting the learners to engage with the subject matter and fellow students. The vagueness of the notion of assessing the quality of contributions is a problem that might be anticipated as being fairly common amongst potential users, and so illustrates the type of problem that future versions of the toolkit could be designed to anticipate and address. 
Table 1

Selected WoZ interactions with Participant 1

\begin{tabular}{|l|l|}
\hline \multicolumn{2}{|l|}{ Question } \\
\hline \multicolumn{2}{|l|}{ Participant response } \\
\hline $\begin{array}{l}\text { 1. What is the context for this dialogue? (What is } \\
\text { the course? Who is on it? Which part of the course } \\
\text { is it used on, etc.) }\end{array}$ & $\begin{array}{l}\text { The context is a module called human-computer } \\
\text { interaction with about 200 students and the } \\
\text { interactive discussion are used for group work and } \\
\text { discussing approaches to coursework etc. }\end{array}$ \\
\hline $\begin{array}{l}\text { 2. What is your broad aim for this part of the } \\
\text { course? }\end{array}$ & $\begin{array}{l}\text { That students should be able to communicate their } \\
\text { methods for evaluating software. }\end{array}$ \\
\hline $\begin{array}{l}\text { 3. For the part of the course where the discussion is } \\
\text { used, what are your learning objectives? }\end{array}$ & $\begin{array}{l}\text { Students should be able to initiate and respond to } \\
\text { dialogue about HCI, to contribute to group } \\
\text { discussions about strategies, research etc. }\end{array}$ \\
\hline $\begin{array}{l}\text { 4. For each of the learning objective, how will you } \\
\text { know when they have been achieved? }\end{array}$ & $\begin{array}{l}\text { By reading the record of interactions within } \\
\text { WebCT and assessing the quality of their } \\
\text { contributions. }\end{array}$ \\
\hline
\end{tabular}

Not all of the exchanges were successful, however. Rather than following the expected rationalist reduction from broad course aims to the specific learning objectives for each piece of dialogue, Participant 4 (from Dentistry) responded to the prompt, "For this part of the course, what are your learning objectives? For each of these, how will you know when they have been achieved?" as follows:

“This sounded a bit like TQA [Teaching Quality Assessment] so I've cheated a bit and used the objectives and assessments I wrote for the basic epidemiology element before it became Web based. I believe it is still correct and does the job OK. I began to wonder though if it is a bit stiff and limited.” 
This was followed by a page-long excerpt of aims taken from course validation documents. Clearly, this did not meet the needs of the elicitation process, widening out the description rather than refining it. This potential for confusion between the process of detailed description and the language used in quality assurance documentation is something that will be addressed by refining the prompts and incorporating opportunities for users to call up sample responses that exemplify the type of response required.

\subsection{Mapping participants' design needs against the analytical framework}

In order to illustrate the relevance of the model, examples from the study have been mapped against the analytical framework (the five criteria identified in section 4.2) used to structure the toolkit. This mapping is illustrated in Table 2, below. 
Table 2

Mapping design needs against the analytical framework

\begin{tabular}{|c|c|c|c|c|}
\hline & Participant 1 & Participant 2 & Participant 3 & Participant 4 \\
\hline $\begin{array}{l}\text { Open/closed } \\
\text { domain }\end{array}$ & $\begin{array}{l}\text { "interactive discussion are } \\
\text { used for group work and } \\
\text { discussing approaches to } \\
\text { coursework etc." }\end{array}$ & $\begin{array}{l}\text { "The context of the dialogue in my } \\
\text { module is such that students can elicit and } \\
\text { negotiate requirements" }\end{array}$ & $\begin{array}{l}\text { "a method that involves discussion to } \\
\text { evolve/discover (?) knowledge rather than } \\
\text { the transmission of information. But i am } \\
\text { not very familiar with the term. In my own } \\
\text { teaching dialogue is used as a part of the } \\
\text { delivery but it isn't central to it." }\end{array}$ & $\begin{array}{l}\text { "I could get my head round } \\
\text { the approaches when there } \\
\text { was a right answer but had } \\
\text { much more difficulty when } \\
\text { there wasn't" }\end{array}$ \\
\hline $\begin{array}{l}\text { Collaboration } \\
\text { or competition }\end{array}$ & $\begin{array}{l}\text { "To be able to engage in } \\
\text { discussion by initiating and } \\
\text { responding to constructive } \\
\text { argument and information } \\
\text { sharing." }\end{array}$ & $\begin{array}{l}\text { "It should promote on-line } \\
\text { debate/research skills with some } \\
\text { reflection from students regarding their } \\
\text { learning. It should also encompass } \\
\text { aspects of Problem-Based Learning } \\
\text { fostering deep approach to learning by the } \\
\text { students." }\end{array}$ & $\begin{array}{l}\text { "They report on what they have discovered } \\
\text { and give each feedback via a discussion } \\
\text { list." }\end{array}$ & \\
\hline Duration & Over several weeks & Over several weeks & $\begin{array}{l}\text { "It is used throughout the course but is } \\
\text { probably most used when working on } \\
\text { courseworks" }\end{array}$ & $\begin{array}{l}\text { "The first term of the } \\
\text { programme" }\end{array}$ \\
\hline $\begin{array}{l}\text { Number of } \\
\text { participants }\end{array}$ & "about 200 students" & & & $3-5$ \\
\hline $\begin{array}{l}\text { Power } \\
\text { relationships }\end{array}$ & $\begin{array}{l}\text { Tutor not viewed as a } \\
\text { participant in the } \\
\text { discussion; no formal roles } \\
\text { assigned }\end{array}$ & $\begin{array}{l}\text { "Dialogue-based teaching is a way of } \\
\text { empowering students in order to be able } \\
\text { to take responsibility for their own } \\
\text { learning, and for the lecturer/tutor to be a } \\
\text { facilitator of such learning" }\end{array}$ & $\begin{array}{l}\text { "They report on what they have discovered } \\
\text { and give each [other] feedback" }\end{array}$ & \\
\hline
\end{tabular}


A number of issues emerged from completing this mapping process. Firstly, not all participants were equally well able to specify what their requirements were. In some cases, this reflected a level of awareness about the issues involved in using dialogue to support learning - as clearly indicated, for example, by the comments of Participant 4, in Table 2, about whether or not the domain was open or closed. Importantly, this highlights the analytical value of the framework as a way of exploring users' current awareness.

Secondly, only one participant (i.e. Participant 1, in Table 2) addressed all five elements of the framework. The 'blanks' in Table 2 need to be considered in further work, to see whether these were accidental omissions that need further thought or were areas that were deliberately left open since they were not a primary concern for the participant.

Another issue that arose was that participants were not equally able to engage with the language and terminology used in the area. For example, Participant 2 was familiar with problem-based learning, which is essentially a collaborative pedagogic technique (Savin-Baden, 2000) - however, this quality remained tacit in his discussion. On a related issue, Participant 1 engaged on the level of pedagogic aims, not on the level of methods through which these could be achieved. However, the question about assessing the quality of interaction did require him to address this issue by responding at a detailed and practical level.

One particular benefit of the toolkit was that it highlighted differences between participants' espoused theories and their practice. For example, Participant 3 talked about discussion as a way to evolve or discover knowledge, but when describing his pedagogy in more detailed terms he characterised the discussion as exchanges of 
information, and spoke of "dialogue for delivery". Whilst the toolkit cannot detect these discrepancies, and certainly cannot take a general moral stance on the relative merits of particular practices, it does require the user to articulate their actual pedagogic practices - thus it can promote the self-explanation effect (Chi, Bassok, Lewis, Reimann \& Glaser, 1989). There is evidence that some participants benefited more from this than others: Participant 1 became aware of the shortcomings of his current practice (see section 5.3), whereas Participant 2 did not respond (within the context of the WoZ study) with any evidence of reflection on his initial position.

\subsection{What impact did the approach have?}

The rationale for developing toolkits is that they should be useful - they should scaffold the design process and thus allow practitioners to achieve more than would otherwise have been possible. Following the completion of the plan, participants were invited to comment on the process and to say how (if at all) they had found it useful.

“The answer [to the question, "Have you changed your approach?"] is yes.

I have not found a satisfactory way of balancing the use of on-line discussion with allegedly face-to face teaching and tutorials. That's why I include the VLE as part of the log - some students do excellent written logs and engage in the tutorial. They cannot be penalised vis-a-vis the student who uses the VLE (nor vice versa). That's why my criteria are vague."

This excerpt illustrates Participant 1's conceptual development - moving from the view of dialogue as a relatively unproblematic format amenable to measurement to a more 
critical view that included the relative ability of students and the need to mix discursive media in order to address the problems of each.

Participant 4 also felt the experience to be both useful and educationally beneficial. In response to the same question, she said:

"I would have planned (and implemented) discussion areas differently if I'd had access to this sort of guidance. It was interesting, certainly made me think and was not superficial."

As with Participant 1, she also showed evidence of having developed a more sophisticated conception of the educational potential of dialogue within her discipline, which is currently taught in a didactic, transmissive format.

"It brought out some interesting points that made me think about the discussion area. I remembered the point ... about introducing students to the fact that there are often no right/wrong answers. Maybe it is a bigger culture change than we think in dentistry to teach this, especially when training systems are so competency based and we have "clinical guidelines", which might be termed "clinical right answers" in some cases... Then I started thinking about shouldn't it be all equal but because there are some wrong areas we may end up being led by the blind ..."

Similarly, Participant 1 began to question the drive by their institution's management towards the adoption of online learning in mainstream courses.

"Thanks for making me think real hard about this ... On reflection the key issue I need to address is why use a VLE for 'full time' students?" 
These excerpts illustrate that the use of the toolkit resulted in two main areas of impact: firstly, it provided a short-term benefit in terms of helping some of the users develop plans for the use of dialogue to support learning that would otherwise have been beyond their ability, and secondly, it provided a long-term benefit by prompting them to reflect on their aims and understanding of the role of dialogue in relation to their practice.

\subsection{Identification of potential refinements}

Although the use of the toolkit was viewed positively by participants, some problems were encountered. As noted above, for example, Participant 4 was led astray by the use of terminology normally associated with Teaching Quality Assessment. In light of these problems, some of the prompts used have been refined and illustrative responses will be prepared to guide users as and if needed.

Similarly, one of Participant 1's responses (concerning the judgment of quality of students' discussion) was too vague to be easily interpreted by the framework used in the toolkit. Although the interactions supported Participant 1's conceptual development (in terms of realising why their criteria were vague), the process did little to help them develop an appropriate plan for implementation. Identification of common problems, such as this, with links to a 'troubleshooting' resource (incorporating advice and case studies) would be a valuable addition to the toolkit.

Another area in need of development is the information currently available to users about each of the methods.

"I would definitely need to look up more detailed definitions and case studies." (Participant 4) 
Finally, as noted above, the toolkit currently only incorporates a relatively small selection of approaches to using dialogue in education. It will be necessary to expand this - and to develop a method to support user-defined additions to the database - for the refined version of the tool.

\subsection{Discussion}

The increasing use of dialogue in learning, and the difficulties of effectively implementing these techniques, combine to create a particular issue for research: in order to help practitioners engage meaningfully and effectively with this topic, it is necessary to cut down the options that they must consider in a way which reflects (rather than restricts) their specific concerns and requirements. In order to address this issue, we analysed the pedagogic design process and the essential features of the different approaches to using dialogue, and used this as the basis for the design of a decision support tool. However, we recognise that this particular analysis represents one possible view of this topic; whilst it would be perfectly possible to produce alternative analyses, our concern was simply to investigate whether or not the model we had derived was useful to practitioners.

The study described above was designed to examine whether practitioners with limited experience of dialogic methods could use the decision support tool to design or redesign their teaching in order to bring dialogue more prominently into their instruction. Essentially, the study was intended to consider whether the approach we had adopted was viable, and to identify any issues that arose through practitioners' use of the tool.

Although the study only involved a small sample of potential users, it did demonstrate that practitioners with a range of different teaching needs and relevant experience could successfully use the tool to introduce dialogue into their teaching. There was also 
evidence that use of the tool prompted reflection upon their prior experiences of having used dialogue to support learning in less systematic ways. These findings are consistent with studies of similar decision support tools for other design processes (e.g. Conole et al., 2001). In addition, a number of issues were identified that will influence the success with which users will engage with the tool, including the tendency to provide overgeneral descriptions of their intentions and the problem of reverting to ready-made responses to Quality Assurance Agency reviews rather than describing objectives in their own language and terminology. A more general concern was also raised by the comments of Participant 2: although the tool prompts users to reflect on design issues as part of the decision making process, there are no guarantees that this reflective stance will continue beyond the period of their engagement with the tool. Such general concerns could form the basis for future research on the longitudinal impact of decision support tools of this type.

\section{Conclusion and further work}

Although dialogue is an important and valuable way of supporting learning, its use is problematic, and is likely to remain so for the foreseeable future. The toolkit described in this paper represents one way of helping practitioners to overcome these problems. As illustrated in the study above, the approach has both short and long-term benefits, helping practitioners both to plan new ways to incorporate dialogue in their courses and also to use the design process as a prompt to reflection that enabled them to develop an increasingly sophisticated appreciation of the role of dialogue in their discipline.

The study validated the general principle of using a toolkit to support the design process. However, it also highlighted a number of refinements that will be required 
during the implementation of a refined version of the toolkit. Importantly, these requirements were primarily concerned with the language used in the elicitation process and the volume of material currently held in the toolkit database, rather than the conceptual structure of the resource. Indeed, the analytical framework provided a useful diagnostic tool when study participants' design needs were mapped on it. This provides

a first level of empirical support for the pragmatic decisions required to structure the knowledge base. However, further studies with a wider sample of users and a greater volume of database content will be required before these decisions can be fully supported. In addition, it remains necessary to develop a way of allowing users to contribute both database content and completed implementation plans to the toolkit.

Whilst practical work clearly still remains before this toolkit can fulfill its aim of helping academics to use dialogue as part of their teaching practice, the conceptual development described in this paper represents an important step towards this aim. However, it is also important to recognise its contribution to wider research issues, both by exemplifying the process through which toolkits can be developed, but perhaps more importantly, by using this work to engage in a process of conceptual development that provides a better understanding of the relative merits of different ways of using dialogue to support learning.

\section{Acknowledgements}

Our thanks to colleagues who took part in the study and to the reviewers for their helpful comments. 


\section{References}

Baker, M. (1989). Negotiated Tutoring: An Approach to Interaction in Intelligent Tutoring Systems. Unpublished Ph.D. Thesis, Centre for Information Technology in Education, Thesis No. 7, The Open University.

Boyle, T. \& Cook, J. (2001). Online Interactivity: Best Practice Based on Two Case-Studies. Association for Learning Technology Journal, ALT-J, 9(1), 94-102.

Chi, M. T. H., Bassok, M., Lewis, M., Reimann, P. and Glaser, R. (1989). Self-Explanation: How Students Study and Use Examples in Learning to Solve Problems. Cognitive Science, 13, 145-182.

Collins, A. \& Stevens, A. L. (1991). A Cognitive theory of Inquiry Teaching. In P. Goodyear (Ed.), Teaching Knowledge and Intelligent Tutoring, 203-230. Norwood, NJ: Ablex.

Conole, G., Crewe, E., Oliver, M. \& Harvey, J. (2001). A Toolkit for Supporting Evaluation. ALT-J, 9 (1), in press.

Conole, G. \& Oliver, M. (in press). Embedding Theory into Practice Using Toolkits. Journal of Interactive Media in Education.

Cook, J. (2001). Bridging the Gap Between Empirical Data on Open-Ended Tutorial Interactions and Computational Models. International Journal of Artificial Intelligence in Education, 12, 85-99.

Derry, S. (1992). Metacognitive Models of Learning and Instructional Systems Design. In M. Jones \& P. Winne, (Eds.), Adaptive Learning Environments: foundations and frontier. Hamburg: SpringerVerlag.

Faulkner, X. (2000). Usability Engineering. Wiltshire: Macmillan Press Ltd.

Harasim, L. (2001). The Future of Learning (Keynote Lecture). In CAL 2001 Learning across the ageslooking back and looking forwards, Abstract Book, p. 39. Elsevier Science.

Levin, J. A. \& Moore, J. A. (1977). Dialogue-Games: Metacommunication Structures for Natural Language Interactions. Cognitive Science, 1(4), 395-420.

Lipman, M. (1991). Thinking in Education. New York: Cambridge University Press.

Oliver, M. \& Conole, G. (1999) From Theory to Practice: A Model and Project Structure for Toolkit Development. BP ELT Report No. 12, University of North London.

Plato (1924). Laches, Protagoras, Meno, and Euthydemus. (W. R. M. Lamb, trans.) Cambridge, MA: Harvard University Press. 
Savin-Baden, M. (2000). Problem-Based Learning in Higher Education: Untold Stories.

Buckinhamshire: Open University Press.

Stevens, A. L., Collins, A. \& Goldin, S. E. (1982). Misconceptions in Students' Understanding. In D. H.

Sleeman \& J. S. Brown (Eds.), Intelligent Tutoring Systems, 13-24. London: Academic Press.

Vygotsky, L. S. (1978). Mind in Society. The Development of Higher Psychological Processes. Edited by

M. Cole, V. John-Steiner, S. Scribner \& E. Souberman. Cambridge, Mass.: Harvard University Press. Winkels, R. (1992). Explorations in Intelligent Tutoring and Help. Amsterdam: IOS Press. 